\title{
Noonan's and DiGeorge syndromes with monosomy 22q11
}

\author{
D I Wilson, S Bennett Britton, C McKeown, D Kelly, I E Cross, S Strobel, P J Scambler
}

\begin{abstract}
A boy with the dysmorphic features of Noonan's syndrome and pulmonary valve stenosis who had evidence of hypoparathyroidism and abnormal $T$ lymphocyte numbers in the neonatal period is reported. He had a normal karyotype but molecular analysis revealed a submicroscopic deletion within chromosome 22q11, the region deleted in DiGeorge syndrome. Thus this child has both Noonan's syndrome and DiGeorge syndrome; $22 \mathrm{q} 11$ is a candidate region for a gene defective in Noonan's syndrome.
\end{abstract}

(Arch Dis Child 1993;68:187-9)

Noonan's syndrome is an autosomal dominant disorder comprising short stature, congenital heart defects, chest deformities, short webbed neck, and dysmorphic facial appearance. ${ }^{1-3}$ The facial features of the syndrome are ptosis, hypertelorism, epicanthic folds, down slanting palpebral fissures, micrognathia, and low set posteriorly rotated ears. The commonest cardiac abnormality in this condition is pulmonary stenosis, which occurs in $50 \%$ of cases but atrial septal defects, ventricular septal defects, and asymmetrical septal hypertrophy have also been described in Noonan's syndrome. ${ }^{3-5}$ The characteristic deformity of the thorax is pectus carinatum superiorly and pectus excavatum inferiorly. Undescended testes are a frequent finding in affected males. ${ }^{3} \mathrm{~A}$ history of abnormal bruising or bleeding is common. Activated partial thromboplastin time is prolonged in $40 \%$ of cases and specific abnormalities in the intrinsic pathway of coagulation occur in $50 \%$ of cases. ${ }^{6-8}$ Delayed bone age is found in $20 \%$ of cases of Noonan's syndrome. ${ }^{2} 38$

DiGeorge syndrome is a congenital anomaly consisting of aplasia or hypoplasia of the thymus and parathyroid glands, outflow tract defects of the heart, and dysmorphic facies. ${ }^{9}$ The heart defects most frequently found are interrupted aortic arch type B, truncus arteriosus, and Fallot's tetralogy. ${ }^{10}$ The dysmorphic facial features are hypertelorism, short palpebral fissures, small mouth, short philtrum, micrognathia and low set, posteriorly rotated ears. Recent work has shown that the majority of patients with DiGeorge syndrome have a deletion within chromosome 22q11. 112

The clinical features of Noonan's and DiGeorge syndromes are relatively distinct and there have been no previous reports of these syndromes occurring together.

We now describe a child with a molecular deletion of chromosome 22q11 who had features of both Noonan's syndrome and DiGeorge syndrome (table 1).

\section{Case report}

The proband was the third offspring of unrelated white parents. Their first child was a girl who was stillborn at 30 weeks' gestation with a retroplacental haemorrhage; the second child was a healthy boy. The proband was delivered at 36 weeks' gestation weighing $2320 \mathrm{~g}$. Bilateral undescended testes were noted at birth. He became jittery on day 6 and was found to have a serum calcium concentration of $1.28 \mathrm{mmol} / 1$ (normal range $2 \cdot 20-2.65 \mathrm{mmol} / \mathrm{l}$ ). This was treated with oral calcium supplementation and alpha-1-calciferol. The alpha-1-calciferol was discontinued after one month but his oral calcium supplementation was continued to maintain normal calcium concentrations.

At 4 weeks of age he was found to have a low percentage of $\mathrm{T}$ lymphocytes with total number of CD3 lymphocytes of $8 \%$, CD4 4\%, and CD8 $2 \%$. They were repeated at 4 months and the total $\mathbf{T}$ lymphocyte count was low but had increased to CD3 35\%, CD4 30\%, CD8 9\%. T lymphocyte numbers at 2.5 and 6 years of age had further increased but were still below the normal range. In vitro responses to phytohaemagglutinin were normal from 4 months of age. He had one episode of oral candidiasis but has not had severe or recurrent infections.

A murmur was heard in the neonatal period and echocardiography demonstrated a patent ductus arteriosus and a patent foramen ovale. Echocardiography was repeated at 3 years of age and the ductus arteriosus and foramen ovale were no longer patent but a mild degree of pulmonary valve stenosis was found.

Table 1 Features of DiGeorge syndrome and Noonan's syndrome found in proband

\begin{tabular}{lll}
\hline Features found in proband & $\begin{array}{l}\text { DiGeorge } \\
\text { syndrome }\end{array}$ & $\begin{array}{l}\text { Nooman's } \\
\text { syndrome }\end{array}$ \\
\hline Hypertelorism & + & + \\
Ptosis & - & + \\
Down slanting palpebral fissures & - & + \\
Low set ears & + & + \\
Posteriorly rotated ears & + & + \\
Low hair line & - & + \\
Wide spaced nipples & - & + \\
Undescended testes & - & + \\
Pulmonary valve stenosis & + & + \\
Short stature & - & + \\
Prolonged APTT & & + \\
Delayed bone age & - & + \\
Hypocalcaemia & - & + \\
Treell deficiency & + & - \\
22qll deletion & + & - \\
\hline
\end{tabular}

London

S Strobel

Correspondence to:

Dr Wilson.

Accepted 13 August 1992 
At the age of 5 years his height was $90.6 \mathrm{~cm}$ (4 SD below the mean). His growth curves for both height and weight had run parallel to the 3rd centile lines from a few months of age. His bone age was $2 \cdot 1$ years at a chronological age of 4 years.

His dysmorphic features at the age of 3 years were hypertelorism, down slanting palpebral fissures, inferior epicanthic folds, flat nasal bridge, and low set and posteriorly rotated ears with deficient upper helixes. His posterior hair line was low with a short neck. He had widely spaced nipples. Figures $1 \mathrm{~A}$ and $\mathrm{B}$ show his appearance at 6 years.

He was noted to bruise easily and had a prolonged activated partial thromboplastin time (APTT) of $\mathbf{4 0}$ secs (control 32 secs, upper limit of normal $37 \mathrm{secs}$ ). His prothrombin time, total clotting time, and fibrinogen concentration were all within normal limits.

At the age of 6 years he attends a normal school but is functionally one year behind. Both his parents are well and neither have any features of Noonan's syndrome or DiGeorge syndrome.

\section{Investigations}

Chromosome analysis was carried out on metaphases with greater than 850 bands per haploid set. ${ }^{13}$ There was no visible cytogenetic abnormality in the proband or his parents. Filters were prepared by Southern blotting and hybridised with the DNA probes 22.71 and XV2C (D7S23). Probe 22.71 has been mapped to $22 \mathrm{qll}$ and is deleted in a proportion of patients with DiGeorge syndrome ${ }^{14}$ and XV2C was used as a control probe. Preparation of the filter and densitometric analysis was carried out by the method described previously. ${ }^{14}$ The result is shown in fig 2 .

The band intensities of radiolabelled filters were also analysed by a second method using a phosphoimager (Molecular Dynamics). Filters were exposed against phosphor screens and the resultant image analysed using ImageQuant software. The results obtained are shown in table 2 and refer to arbitrary phosphoimager

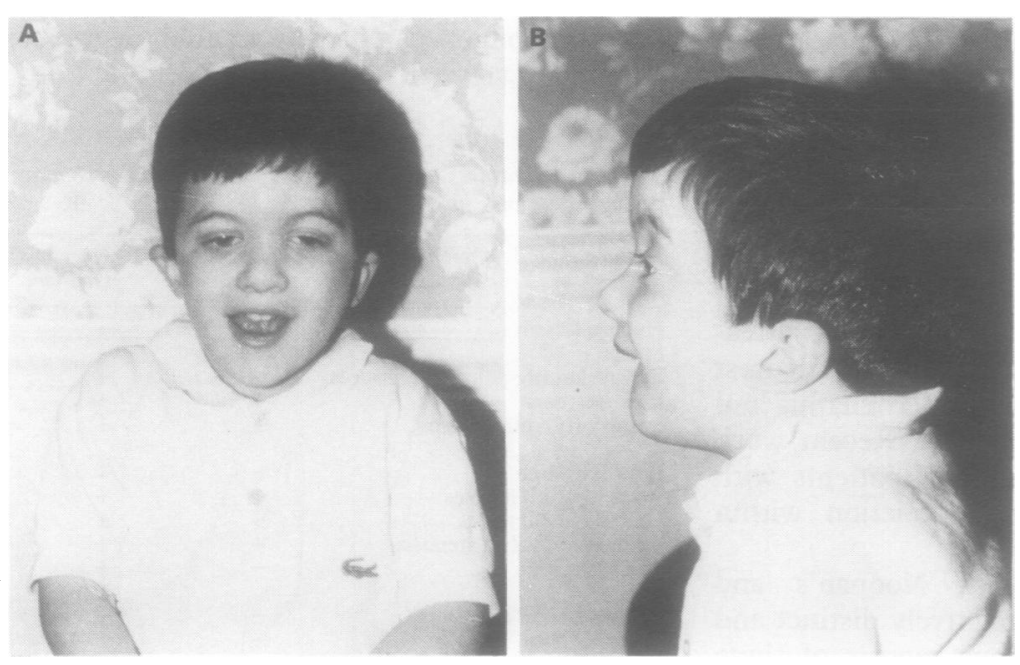

Figure 1 These photographs of the proband aged 6 years show the ptosis, epicanthic folds, down slanting palpebral fissures, short neck, and low set, posteriorly rotated ears.

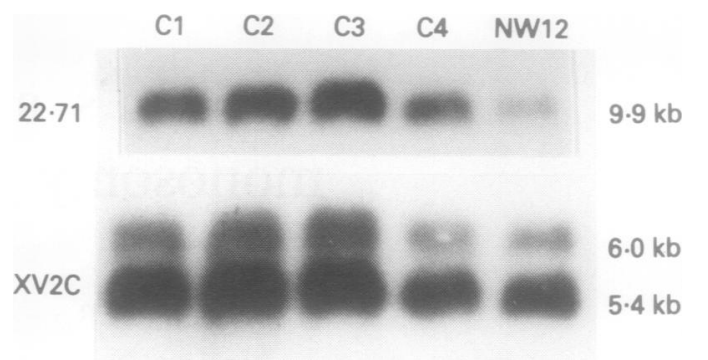

Figure 2 Autoradiograph showing the Southern blot analysis: 22.71 (chromosome 22 probe) detects a $9 \cdot 9$ kilobase (kb) band and XV2C (D7S23, control probe) detects two bands, $5.4 \mathrm{~kb}$ and $6.0 \mathrm{~kb}$ in size. Tracks $\mathrm{Cl}, \mathrm{C2}, \mathrm{C3}$, and $C 4$ contains different quantities of DNA from normal individuals and act as control lanes. Track NW12 contains DNA from the proband. The intensities of the control bands $(X V 2 C)$ in track NW12 are approximately equal to those in track C4. However the intensity of band 22.71 in the proband is half the intensity of the controi track C4.

Table 2 Table shows the results from the phosphoimager analysis of bands 22.71 and $X V 2 C$ in control and proband (NW12) lanes from two separate radiolabelled filters (filters $A$ and $B)$. The units are phosphoimager counts. In filter $A$ the count for band 22.71 of NW12 is $55 \%$ of the corrected control value and in filter $B$ it is $48 \%$

\begin{tabular}{lllll}
\hline & \multicolumn{2}{l}{ Filter A lanes } & \multicolumn{2}{l}{ Filter B lanes } \\
\hline Probe & Control & NW12 & Control & NW12 \\
XV2C & 238877 & 222936 & 269107 & 284128 \\
22.71 & 266935 & 136155 & 421099 & 210342 \\
\hline
\end{tabular}

counts for the bands detected by each of the probes. They confirm that there is a $50 \%$ reduction in intensity of band 22.71 in the proband compared with matched control lanes.

\section{Discussion}

This child has both DiGeorge syndrome and Noonan's syndrome. The dysmorphic features in the child-ptosis, epicanthic folds, downslanting palpebral fissures, short neck, and widely spaced nipples-are characteristic of Noonan's syndrome. Similarly undescended testes, delayed bone age and short stature are also common findings. The cardiac abnormality detected on echocardiography, pulmonary valve stenosis, is the commonest heart lesion in Noonan's syndrome. Pulmonary valve stenosis has not been documented as an isolated findings in DiGeorge syndrome in the literature but we have seen it in one other child with DiGeorge syndrome in a series of 36 cases (unpublished data). Prolonged APTT is a common finding in Noonan's syndrome. Abnormal $T$ cell function and hypocalcaemia along with a deletion of chromosome 22q11 are diagnostic of DiGeorge syndrome. This is the first report of these two conditions occurring together, although there has been a single case report of an adult with hypoparathyroidism was reported to have the dysmorphic features of Noonan's syndrome, ${ }^{15}$ unfortunately no photograph was included in this report.

There are a number of possible explanations for the conditions occurring together. The simplest explanation is that the proband had both conditions purely by chance. Alternatively the Noonan's phenotype may have been a con- 
sequence of aberrant development of the third and fourth pharyngeal pouch derivatives in DiGeorge syndrome. It has been proposed that the facial features of Noonan's syndrome result from oedema of the face and neck during development. It has been demonstrated that neck webbing in Noonan's syndrome follows regression of cystic hygromata, ${ }^{16} 17$ and thus obstruction of the jugular lymphatic vessels is thought to play a part in development of the phenotype. Disturbance of third and fourth pharyngeal arch development and thus the outflow tract of the heart may cause neck and facial oedema in some instances. Oedema of the upper part of the body could explain the facial features but does not provide an explanation for the short statue, delayed bone age, prolonged APTT, or genital abnormalities seen in this child. The fact that there are many children with equivalent pulmonary valve stenosis who do not have Noonan's phenotype is also against this hypothesis as an explanation for our case. Another explanation of the observation would be that more than one gene is deleted in the proband and that one of the deleted genes is responsible for the Noonan's phenotype. However, the deletion in this child is submicroscopic and none of the children with visible 22q11 interstitial deletions and DiGeorge syndrome that we have seen has Noonan's syndrome. It is also possible that several minor genes contribute to the Noonan's phenotype in addition to a major gene that is defective in the autosomal dominant families and that the gene defective in DiGeorge syndrome has a minor contribution to the Noonan's syndrome.

A group of patients with the Noonan's phenotype also have features of neurofibromatosis. Recent investigation of a family with features of both Noonan's syndrome and neurofibromatosis had revealed a large deletion in the neurofibromatosis gene on chromosome $17 q 11.2^{18}$ However linkage studies with 17 q11.2 probes have not confirmed linkage of the classical Noonan's phenotype to this region. ${ }^{19}$

It is clear from the work in the Noonan's neurofibromatosis families that more than one developmental abnormality can lead to the Noonan's syndrome; $22 \mathrm{q} 11$ is a further candidate region that might warrant investigation in certain Noonan's syndrome families.

We wish to thank the child and his parents for their help and cooperation. Written permission was obtained to publish the photographs and ethical permission was obtained for the analysis to be performed.

We also wish to thank Dr Di Giovanni, Dr Storr, Dr Rayner, We also wish to thank Dr Di Giovanni, Dr
and Mr Johnson for providing clinical details.

DIW is supported by the British Heart Foundation and the
Drohnson for providing clinical details. DIW is supported by the British Heart Foundation and the
Borwick Trust. PJS is supported by Action Research, the British Heart Foundation and the Medical Reserch Council.

1 Mendez HMM, Optiz JM. Noonan syndrome: a review. Am f Med Genet 1985;21:493-506.

2 Allanson JE. Noonan syndrome. $\mathcal{F}$ Med Genet 1987;24:9-13.

3 Sharland M, Burch M, McKenna WM, Patton MA. A clinical study of Noonan syndrome. Arch Dis Child 1992;67: 178-83.

4 Pernot C, Worms AM, Marcon F, Gilgenkrantz S, Leheup B. Le syndrome de Noonan et sa dysplasie cardio-vasculaire. A propos de 64 observations. Pediatrie $1989 ; 44: 437-47$.

5 Sanchez-Cascos A. The Noonan syndrome. Eur Heart f 1983; 4:223-229.

6 De Haan M, vd Kamp JJP, Briet E, Dubbeldam J. Noonan syndrome: partial factor XI deficiency. Am $\mathcal{f}$ Med Gene 1988;29:277-82.

7 Kitchens CS, Alexander JA. Partial deficiency of coagulation factor XI as a newly recognized feature of Noonan syndrome. F Pediatr 1983;102:224-7.

8 Sharland M, Patton MA, Talbot S, Chitolie A, Bevan DH Coagulation-factor deficiencies and abnormal bleeding in Noonan's syndrome. Lancet 1992;339:19-21.

9 Conley ME, Backwith JB, Mancer JFK, Tenckhoff L. The spectrum of the DiGeorge syndrome. 7 Pediatr 1979;94: 883-90.

10 Van Mierop LHS, Kutsche LM. Cardiovascular anomalies in DiGeorge syndrome and importance of neural crest as a DiGeorge syndrome and importance of neural crest as a

11 Carey AH, Roach S, Williamson R, et al. Localization of 27 DNA markers to the region of human chromosome 22q11-pter deleted in patients with the diGeorge syndrome and duplicated in the der22 syndrome. Genomics 1990;7: $299-306$.

12 Scambler PJ, Carey AH, Wyse RKH, et al. Microdeletions within 22q11 associated with sporadic and familial DiGeorge syndrome. Genomics 1991;10:201-6.

13 Standing Committee on Human Cytogenetic Nomenclature. An international system for human cytogenetic nomenclature (1985). Basle: S Karger, 1985.

14 Carey AH, Clausen U, Ludecke HJ, et al. Investigation of deletion in DiGeorge syndrome detected from microclones from 22q11. Mammalian Genome 1992;3:101-5.

15 Rudge P, Neville BGR, Lascelles PT. A case of Noonan's syndrome and hypoparathyroidism presenting with epilepsy. F Neurol Neurosurg Psychiatry 1974;37:108-11.

16 Donnenfeld AE, Nazir MA, Sindoni F, Librizzi RJ. Prenata sonographic documentation of cystic hygroma regression in Noonan syndrome. Am $\mathcal{f}$ Med Genet 1991;39:461-5.

17 Verloes A, Guidi O, Frederic J, Lambotte C. Noonan and Klinefelter syndromes in a child. Am $\mathcal{F}$ Med Genet 1987;27: 727-8.

18 Colley $\mathrm{P}$, Colley A, Donnai D, et al. Large scale mutations at the NFI locus in Noonan-NFI and NFI patients. Am $\mathcal{F}$ Hum Genet 1991;49:21 (abstract)

19 Sharland M, Taylor R, Patton MA, Jeffery S. Absence of linkage of Noonan syndrome to the neurofibromatosis type I locus. F Med Genet 1992;29:188-90. 